\title{
Decreased Plasma BDNF Levels of Patients with Somatization Disorder
}

\author{
Nam-In Kang ${ }^{1}$, Jong-II Park ${ }^{2,3}$, Yong-Ku Kim ${ }^{4}$, and Jong-Chul Yang ${ }^{2,3} \bowtie$ \\ 'Department of Psychiatry, Maeumsarang Hospital, Wanju, Republic of Korea \\ ${ }^{2}$ Department of Psychiatry, Chonbuk National University Medical School, Jeonju, Republic of Korea \\ ${ }^{3}$ Research Institute of Clinical Medicine of Chonbuk National University-Biomedical Research Institute of Chonbuk National University Hospital, \\ Jeonju, Republic of Korea \\ ${ }^{4}$ Department of Psychiatry, Korea University Ansan Hospital, Korea University College of Medicine, Ansan, Republic of Korea
}

\begin{abstract}
Objective Brain-derived neurotrophic factor (BDNF), one of the most abundant and important neurotrophins, is known to be involved in the development, survival, maintenance, and plasticity of neurons in the nervous system. Some studies have suggested that BDNF may play a role in the pathophysiology of several psychiatric illnesses such as depression and schizophrenia. Similarly, it is likely that the alteration of BDNF may be associated with the neuro-modulation that contributes to the development of somatization disorder.

Methods The purpose of this study was to determine whether there is an abnormality of plasma BDNF levels in patients with somatization disorder, and to analyze the nature of the alteration after pharmacotherapy using an enzyme-linked immunosorbent assay (ELISA).

Results The plasma BDNF levels of the patients with a somatization disorder were significantly lower compared with those of the control volunteers $(83.61 \pm 89.97 \mathrm{pg} / \mathrm{mL}$ vs. $771.36 \pm 562.14 \mathrm{pg} / \mathrm{mL})$; moreover, the plasma BDNF levels of those patients who received an antidepressant were significantly increased after the treatment $(118.13 \pm 91.45 \mathrm{pg} / \mathrm{mL}$ vs. $72.92 \pm 88.21 \mathrm{pg} / \mathrm{mL})$.
\end{abstract}

Conclusion These results suggest that BDNF may play a role in the pathophysiology of somatization disorder.

Psychiatry Investig 2016;13(5):526-530

Key Words Somatization disorder, BDNF, Neurotrophin.

\section{INTRODUCTION}

Somatization disorder is a chronic illness accompanied by numerous physical complaints regarding various parts of the body and lasts for more than 2 years, resulting in significant impairments of daily life and occupational function. The somatic symptoms usually involve gastrointestinal, cardio-respiratory, urogenital, musculoskeletal, and other internal systems. ${ }^{1-3}$ The psychosocial disability of these patients leads to

Received: August 20, 2015 Revised: December 12, 2015

Accepted: January 8, 2016 Available online: March 28, 2016

$\bowtie$ Correspondence: Jong-Chul Yang, MD, PhD

Department of Psychiatry, Chonbuk National University Medical School, 20 Geonji-ro, Deokjin-gu, Jeonju 54907, Republic of Korea

Tel: +82-63-250-2580, Fax: +82-63-275-3157, E-mail: yangjc@jbnu.ac.kr

$\triangle$ Correspondence: Yong-Ku Kim, MD, PhD

Department of Psychiatry, Korea University Ansan Hospital, Korea University College of Medicine, 122 Jeokgeum-ro, Danwon-gu, Ansan 15355, Republic of Korea

Tel: +82-31-412-5140, Fax: +82-31-412-5144, E-mail: yongku@korea.ac.kr

(a) This is an Open Access article distributed under the terms of the Creative Commons Attribution Non-Commercial License (http://creativecommons.org/licenses/bync/3.0) which permits unrestricted non-commercial use, distribution, and reproduction in any medium, provided the original work is properly cited. reduced productivity and an increased social health care burden. ${ }^{4}$

Brain-derived neurotrophic factor (BDNF) is a member of the nerve-growth-factor family, and plays a critical role in the growth, differentiation, maintenance, and synaptic plasticity of neuronal systems. It is the most abundant of the neurotrophins in the brain and serves as a neuromodulator. ${ }^{5-9}$ There is some evidence of the association between BDNF and several psychiatric illnesses, and of a clinical severity that includes major depression, anxiety disorder, and psychosis. ${ }^{10-15}$ Only a few investigations, however, have examined the relationship between serum BDNF and somatization disorder.

BDNF is also involved in various other mental and physical conditions such as stress, ${ }^{16,17}$ allergic disease ${ }^{18,19}$ and pain. BDNF which serves as a pain modulator plays an important role in pain sensation. ${ }^{20-26}$ Although the pathophysiology of somatization disorder is not clearly identified yet, several studies have suggested that abnormal pain sensation is one of the possible pathogeneses of somatization disorder. ${ }^{13,27-29}$ Moreover, BDNF influences the serotonin neurotransmitters that 
are linked to somatoform disorder and hypochondriasis. ${ }^{12,30-33}$ On these bases, we assumed that there may be some changes of the BDNF levels of the patients with somatization disorder compared with the healthy control volunteers. The aim of the present study was to clarify the magnitudes of the relationships between somatization disorder and serum BDNF.

\section{METHODS}

In this study, we examined the peripheral BDNF levels in the plasma of the following two independent groups: somatization-disorder patients and healthy volunteers. The $27 \mathrm{pa}-$ tients with somatization disorder (mean age: $46.33 \pm 9.73$ years; 12 males and 15 females) who fulfilled the DSM-IV criteria for somatization disorder and the 27 healthy control volunteers (mean age: $46.81 \pm 6.81$ years; 12 males and 15 females) were enrolled in the study. DSM-IV diagnoses were determined from a consensus procedure involving two psychiatrists who used all of the available clinical material including a semistructured interview based on the Diagnostic and Statistical Manual of Mental Disorders, Fourth Edition Revised (DSMIV). ${ }^{34}$ A complete medical history (including allergic history) and physical examination; laboratory tests including urine and blood screens; and an electrocardiogram were obtained from both the patients and the control volunteers. Patients were excluded from the study if a physical illness, comorbid psychiatric illness, any neurological disorder, or abnormal results appeared on the laboratory screening tests. The clinical assessment of the somatization disorder was measured by a Korean version of the Wahler physical symptom inventory (K-WPSI). Patients with major depressive disorder, diagnosed in accordance with the DSM-IV and Beck Depression Inventory (BDI, cut-off score $\geq 21$ ), were excluded from this study. The age- and sex-matched normal control volunteers consisted of randomly selected healthy individuals who visited the University Hospital for regular health screenings. All of the subjects provided written, informed consent after receiving a complete description of the study. The study was approved by the hospital ethics committee (Korea University Ansan Hospital and Chonbuk University Hospital, Korea), and the study procedures were in accordance with Helsinki
Declaration of 1975, as revised in 1983.

Between 8.00 and 9.00, $10 \mathrm{~mL}$ of fasting blood from each of the patients was withdrawn into a lithium heparin vacuum tube, and the blood was immediately centrifuged at $3800 \mathrm{rpm}$ for $10 \mathrm{~min}$. Plasma was stored at $-70^{\circ} \mathrm{C}$ until it was thawed for assay. The human BDNF was assayed using the DuoSet ELISA Development System (Catalog number DY248, R\&D Systems, UK). The assay had a detection range from $20 \mathrm{pg} /$ $\mathrm{mL}$ to $4000 \mathrm{pg} / \mathrm{mL}$. All of the assays were performed in duplicate using the manufacturer-recommended buffers, diluents, and substrates. The optical density of the color reaction in the wells was read using a microtiter plate reader (Bio-tek instruments) that was set for $450 \mathrm{~nm}$. The concentrations of the samples in each plate were calculated according to a standard curve and the dilution factor.

All of the numerical values are expressed as the mean \pm standard deviation. The differences of the plasma BDNF levels between the patients and healthy controls were analyzed with a non-parametric Mann-Whitney test using the SPSS 15.0 software package; the statistical significance level was set at $\mathrm{p}<0.05$. We assessed the alteration of the plasma BDNF levels after the pharmacotherapy treatment using the Wilcoxon Signed Ranks test. Of the 27 patients, 22 patients with somatization disorder took the antidepressant medication, most of which are selective serotonin reuptake inhibitors (SSRIs) (fluoxetine: $n=13$, paroxetine: $n=8$ ) but only one patient took the noradrenergic and specific serotonergic antidepressant (NaSSA) medication (mirtazapine). After the medication, the blood sampling was conducted when the Clinical Global Impression-improvement scale (CGI-I) was 3 which means 'minimally improved' between 9 to 16 weeks. The correlations between the BDNF levels and the clinical-assessment-scale scores were examined using the Spearman correlation coefficient.

\section{RESULTS}

The socio-demographic and psychopathological variables of the normal controls and the patients with somatization disorder are shown in Table 1 . The groups were similar in age $(\mathrm{p}=0.897)$, sex ratio $(\mathrm{p}=0.414)$, and BMI $(\mathrm{p}=0.299)$. The BDI

Table 1. Socio-demographic and psychopathological variables of the normal controls and the patients with somatization disorder

\begin{tabular}{lccc}
\hline \multicolumn{1}{c}{ Characteristics } & Normal control (mean \pm SD) & Patients with somatization disorder $($ mean \pm SD) & p-value \\
\hline Age $($ year) & $46.81 \pm 6.81$ & $46.33 \pm 9.73$ & 0.897 \\
Sex $(\mathrm{M} / \mathrm{F})$ & $12 / 15$ & $12 / 15$ & 0.414 \\
BMI $\left(\mathrm{kg} / \mathrm{m}^{2}\right)$ & $22.63 \pm 2.31$ & $23.14 \pm 2.45$ & 0.299 \\
K-WSPSI & $0.87 \pm 0.24$ & $2.21 \pm 0.81$ & 0.000 \\
\hline
\end{tabular}

BMI: Body Mass Index, K-WPSI: Korean version of Wahler Physical Symptom Inventory 
Table 2. Plasma BDNF level difference between the normal controls and the patients with somatization disorder

\begin{tabular}{ccccc}
\hline Variables & Normal control $(\mathrm{N}=27)$ & Patients with somatization disorder $(\mathrm{N}=27)$ & $\mathrm{Z}$ & $\mathrm{p}$-value \\
\hline BDNF $(\mathrm{pg} / \mathrm{mL})$ & $771.36 \pm 562.14$ & $83.61 \pm 89.97$ & -5.735 & $<0.000^{*}$ \\
\hline
\end{tabular}

${ }^{*} \mathrm{p}<0.01$ (Mann-Whitney). BDNF: brain-derived neurotrophic factor

Table 3. Multivariate association between BDNF level (lower vs. higher)* and group (somatization disorder vs. normal control) of participants after adjusting age and gender

\begin{tabular}{lccc}
\hline & OR & $95 \%$ CI & p-value \\
\hline Age & 0.990 & $0.893-1.098$ & 0.850 \\
Gender & & & \\
$\quad$ Female & 1.000 & - & \\
$\quad$ Male & 0.972 & $0.172-5.489$ & 0.974 \\
Group & & & \\
$\quad$ Somatization disorder & 1.000 & - & \\
$\quad$ Normal control & 64.640 & $11.748-355.659$ & $<0.001$ \\
\hline
\end{tabular}

*BDNF was median splitted into lower $(\leq 201.44 \mathrm{pg} / \mathrm{mL})$ vs. higher BDNF (>201.44 pg/mL) groups. BDNF: brain-derived neurotrophic factor

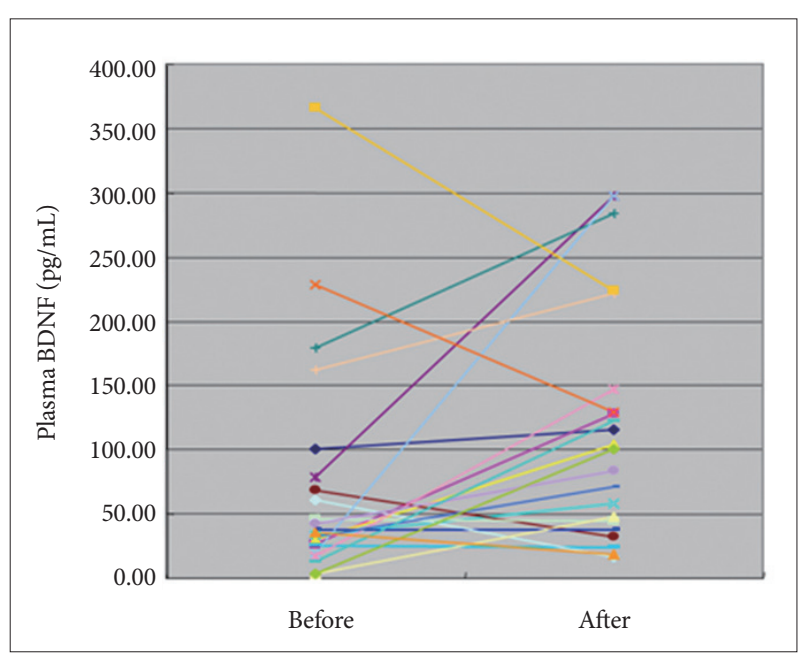

Figure 1. Changes of plasma BDNF level before and after treatment in patients with somatization disorder $(\mathrm{N}=22)$. BDNF: brainderived neurotrophic factor.

score was not clinically severe in both of the groups (normal controls $=3.56 \pm 3.68$; patients with somatization disorder= $12.89 \pm 3.84)$. There was a significant difference of the K-WPSI $(\mathrm{p}=0.000)$. The mean plasma BDNF levels of the 27 patients with somatization disorder were significantly lower compared with those of the controls $(83.61 \pm 89.97 \mathrm{pg} / \mathrm{mL}$ vs. $771.36 \pm$ $562.14 \mathrm{pg} / \mathrm{mL} ; \mathrm{Z}=-5.735 ; \mathrm{p}<0.001$ ), as shown in Table 2.

In multivariate logistic regression analysis (Table 3 ), normal control $(\mathrm{OR}=64.640)$ was significantly associated with higher BDNF level even after controlling for age and gender. In the 22 patients who received pharmacotherapy, their plasma BDNF levels were significantly increased after the antidepressant treatment $(118.13 \pm 91.45 \mathrm{pg} / \mathrm{mL}$ vs. $72.92 \pm 88.21 \mathrm{pg} /$
$\mathrm{mL} ; \mathrm{Z}=-2.029 ; \mathrm{p}=0.042$ ), as shown in Figure 1; however, the clinical-assessment-scale scores did not reveal any significant correlations with the BDNF levels.

\section{DISCUSSION}

Many studies have addressed the clinical importance of BDNF in psychiatric diseases, and significant changes of the plasma BDNF levels for each condition have been demonstrated, ${ }^{35-38}$ furthermore, some of the researchers also reported the recovery of lowered plasma BDNF levels, especially for depressive disorders, after proper treatment. ${ }^{39-41}$ For somatization, however, investigation results regarding the implications of BDNF are extremely rare. The present study showed that somatization disorder was associated with significantly decreased plasma BDNF levels; therefore, a decrease of plasma BDNF levels could constitute a vulnerable marker for disease diagnosis. Our study did not, however, evaluate the relationship between the plasma BDNF levels and somatization-disordersymptom severity, or whether any correlation with the specified clinical assessment subscale existed. Also, we did not conduct an experiment on the plasma BDNF levels in the treatment non-response group, and such experiments are still required to form a definite conclusion.

Somatic symptoms, one of the major features of somatization disorder, are very common in depressive and anxiety disorders, ${ }^{42-46}$ and the comorbidity rate is also very high. ${ }^{47-49}$ Decreased plasma BDNF levels in depressive and anxiety disorders have been observed in many previous studies. ${ }^{11,50,51}$ In this context, our results were achieved in consideration of the previous studies. But, in spite of this meaningful result, we did not completely rule out the effect of stress on plasma BDNF level. As we previously mentioned, there are several reports about the relationship between BDNF and stress. ${ }^{52-55}$ Sometimes, the BDNF reflects the stress condition but in another case, specific genetic status of BDNF also acts as a precipitating factor of stress. So we suggest that further investigations of BDNF in relation to somatization disorder in well controlled sample would be of interest in the future.

We also studied the efficacy of antidepressants in the treatment of 22 patients with somatization disorder, and the condition of the patients after the treatment was evaluated using neuropsychological scales and the plasma BDNF levels. Antidepressant treatment has been shown to enhance the production of plasma BDNF levels; however, despite its previous 
positive results for clinical improvement, we failed to show a statistically significant association between the clinical-assessment-scale scores and the plasma BDNF levels after the antidepressant treatment. One of the possible reasons for why we were unable to produce this association is an insufficient clinical follow-up period; following treatment, we reassessed the plasma BDNF levels after a period that lasted from 9 weeks to 16 weeks. Considering that somatization disorder is a chronic disease that typically lasts for more than 2 years, 9 weeks to 16 weeks is not an adequate time frame for observing the relationship between the plasma BDNF levels and the clinicalassessment-scale scores, so this needs to be addressed in further studies. Also, the number of patients participated in our experiment was too small and the blood samples after the treatment were obtained at different time points between the individuals from 9 to 16 weeks. Furthermore most of the drugs used in this study were SSRIs but there are several other kinds of antidepressants are existed and there is a possibility that they would show another results. Therefore, further clinical investigations with a same and longer time frame and of a larger scale are needed to attain a more precise conclusion about the effect of SSRI treatment on the plasma BDNF levels and clinical-assessment-scale scores for somatizationdisorder patients.

In addition to the previously described limitations, another limitation of this study was identified. The BDNF was apparently capable of crossing the blood-brain barrier, ${ }^{56,57}$ and a positive relationship between the central- and peripheral-blood $\mathrm{BDNF}$ in rats has been reported ${ }^{58}$ however, the cellular origin of human plasma BDNF has not yet been clearly defined. ${ }^{39}$ Therefore, an assessment of plasma BDNF that is circulating in the body, which is not stored in the brain, cannot exactly reflect the BDNF level of the brain. Nevertheless, this study is worthy of notice, as it is the first study to find lower plasma BDNF levels in somatization-disorder patients.

In conclusion, BDNF may play a role in the pathophysiology of somatization disorder. Regarding somatization disorder, however, further studies are needed to clarify the role of BDNF more precisely and its interaction with other vulnerable factors.

\section{Acknowledgments}

This paper was supported by Fund of Biomedical Research Institute, Chonbuk National University Hospital.

\section{REFERENCES}

1. Katon W, Lin E, Von Korff M, Russo J, Lipscomb P, Bush T. Somatization: a spectrum of severity. Am J Psychiatry 1991;148:34-40.

2. Rief W, Hessel A, Braehler E. Somatization symptoms and hypochondriacal features in the general population. Psychosom Med 2001;63:595602.

3. Lipowski ZJ. Somatization: the concept and its clinical application. Am
J Psychiatry 1988;145:1358-1368.

4. Barsky AJ, Orav EJ, Bates DW. Somatization increases medical utilization and costs independent of psychiatric and medical comorbidity. Arch Gen Psychiatry 2005;62:903-910.

5. Anglade P, Tsuji S, Agid Y, Hirsch EC. Neuronal plasticity and Parkinson disease. Mol Chem Neuropathol 1995;24:251-255.

6. Thoenen H. Neurotrophins and neuronal plasticity. Science 1995;270: 593-598.

7. Lindsay RM, Wiegand SJ, Altar CA, DiStefano PS. Neurotrophic factors: from molecule to man. Trends Neurosci 1994;17:182-190.

8. Lewin GR, Barde YA. Physiology of the neurotrophins. Annu Rev Neurosci 1996;19:289-317.

9. Malberg JE, Eisch AJ, Nestler EJ, Duman RS. Chronic antidepressant treatment increases neurogenesis in adult rat hippocampus. J Neurosci 2000;20:9104-9110.

10. Zhivolupov SA, Samartsev IN, Marchenko AA, Puliatkina OV. [The prognostic significance of brain-derived neurotrophic factor (BDNF) for phobic anxiety disorders, vegetative and cognitive impairments during conservative treatment including adaptol of some functional and organic diseases of nervous system]. Zh Nevrol Psikhiatr Im S S Korsakova 2012;112:37-41.

11. Satomura E, Baba H, Nakano Y, Maeshima H, Suzuki T, Arai H. Correlations between brain-derived neurotrophic factor and clinical symptoms in medicated patients with major depression. J Affect Disord 2011;135:332-335.

12. Brondino N, Lanati N, Barale F, Martinelli V, Politi P, Geroldi D, et al. Decreased NT-3 plasma levels and platelet serotonin content in patients with hypochondriasis. J Psychosom Res 2008;65:435-439.

13. Deveci A, Aydemir O, Taskin O, Taneli F, Esen-Danaci A. Serum brainderived neurotrophic factor levels in conversion disorder: comparative study with depression. Psychiatry Clin Neurosci 2007;61:571-573.

14. Zhang XY, Chen DC, Tan YL, Tan SP, Wang ZR, Yang FD, et al. The interplay between BDNF and oxidative stress in chronic schizophrenia. Psychoneuroendocrinology 2015;51:201-208.

15. Valiente-Gomez A, Amann BL, Marmol F, Oliveira C, Messeguer A, Lafuente A, et al. Comparison of serum BDNF levels in deficit and nondeficit chronic schizophrenia and healthy controls. Psychiatry Res 2014;220:197-200.

16. Radahmadi M, Alaei H, Sharifi MR, Hosseini N. Effects of different timing of stress on corticosterone, BDNF and memory in male rats. Physiol Behav 2015;139:459-467.

17. Niknazar S, Nahavandi A, Peyvandi AA, Peyvandi H, Akhtari AS, Karimi M. Comparison of the adulthood chronic stress effect on hippocampal BDNF signaling in male and female rats. Mol Neurobiol 2016;53:4026-4033.

18. Tao F, Zhang F, Huang Z, Sun B, Feng X. [Expression of BDNF mRNA in nasal mucosa with allergic rhinitis rat model]. Lin Chung Er Bi Yan Hou Tou Jing Wai Ke Za Zhi 2010;24:224-226.

19. Zeilinger S, Pinto LA, Nockher WA, Depner M, Klopp N, Illig T, et al. The effect of BDNF gene variants on asthma in German children. Allergy 2009;64:1790-1794.

20. Constandil L, Aguilera R, Goich M, Hernandez A, Alvarez P, Infante C, et al. Involvement of spinal cord BDNF in the generation and maintenance of chronic neuropathic pain in rats. Brain Res Bull 2011;86:454459.

21. Duan B, Liu DS, Huang Y, Zeng WZ, Wang X, Yu H, et al. PI3-kinase/ Akt pathway-regulated membrane insertion of acid-sensing ion channel 1a underlies BDNF-induced pain hypersensitivity. J Neurosci 2012;32: 6351-6363.

22. Herradon G, Ezquerra L, Nguyen T, Wang C, Siso A, Franklin B, et al. Changes in BDNF gene expression correlate with rat strain differences in neuropathic pain. Neurosci Lett 2007;420:273-276.

23. Li CQ, Xu JM, Liu D, Zhang JY, Dai RP. Brain derived neurotrophic factor (BDNF) contributes to the pain hypersensitivity following surgical incision in the rats. Mol Pain 2008;4:27. 
24. Merighi A, Salio C, Ghirri A, Lossi L, Ferrini F, Betelli C, et al. BDNF as a pain modulator. Prog Neurobiol 2008;85:297-317.

25. Obata K, Noguchi K. BDNF in sensory neurons and chronic pain. Neurosci Res 2006;55:1-10

26. Stefani LC, Torres IL, de Souza IC, Rozisky JR, Fregni F, Caumo W. $\mathrm{BDNF}$ as an effect modifier for gender effects on pain thresholds in healthy subjects. Neurosci Lett 2012;514:62-66.

27. Sivik T. Alexithymia and hypersensitivity to touch and palpation. Integr Physiol Behav Sci 1993;28:130-136.

28. Wilhelmsen I. Somatization, sensitization, and functional dyspepsia. Scand J Psychol 2002;43:177-180.

29. Fass R. Functional heartburn: what it is and how to treat it. Gastrointest Endosc Clin N Am 2009;19:23-33, v.

30. Koh KB, Choi EH, Lee YJ, Han M. Serotonin-related gene pathways associated with undifferentiated somatoform disorder. Psychiatry Res 2011;189:246-250.

31. Han C, Pae CU, Lee BH, Ko YH, Masand PS, Patkar AA, et al. Fluoxetine versus sertraline in the treatment of patients with undifferentiated somatoform disorder: a randomized, open-label, 12-week, parallelgroup trial. Prog Neuropsychopharmacol Biol Psychiatry 2008;32:437444.

32. Koh KB, Kim CH, Choi EH, Lee YJ, Seo WY. Effect of tryptophan hydroxylase gene polymorphism on aggression in major depressive disorder and undifferentiated somatoform disorder. J Clin Psychiatry 2012; 73:e574-e579.

33. Van Kempen GM, Zitman FG, Linssen AC, Edelbroek PM. Biochemical measures in patients with a somatoform pain disorder, before, during, and after treatment with amitriptyline with or without flupentixol. Biol Psychiatry 1992;31:670-680.

34. American Psychiatric Association. Diagnostic and Statistical Manual of Mental Disorders, fourth edition. Washington, DC: American Psychiatric Association; 1994.

35. Chang YH, Lee SY, Chen SL, Tzeng NS, Wang TY, Lee IH, et al. Genetic variants of the BDNF and DRD3 genes in bipolar disorder comorbid with anxiety disorder. J Affect Disord 2013;151:967-972.

36. Park MH, Chang KD, Hallmayer J, Howe ME, Kim E, Hong SC, et al. Preliminary study of anxiety symptoms, family dysfunction, and the brain-derived neurotrophic factor (BDNF) Val66Met genotype in offspring of parents with bipolar disorder. J Psychiatr Res 2014;61:81-88.

37. Brunoni AR, Baeken C, Machado-Vieira R, Gattaz WF, Vanderhasselt MA. BDNF blood levels after non-invasive brain stimulation interventions in major depressive disorder: a systematic review and meta-analysis. World J Biol Psychiatry 2014:16:114-122.

38. Yoshimura R, Ikenouchi-Sugita A, Hori H, Umene-Nakano W, Hayashi K, Katsuki A, et al. [Blood levels of brain-derived neurotrophic factor (BDNF) in major depressive disorder]. Seishin Shinkeigaku Zasshi 2010;112:982-985.

39. Lommatzsch M, Zingler D, Schuhbaeck K, Schloetcke K, Zingler C, Schuff-Werner $\mathrm{P}$, et al. The impact of age, weight and gender on BDNF levels in human platelets and plasma. Neurobiol Aging 2005;26:115-123.

40. Gervasoni N, Aubry JM, Bondolfi G, Osiek C, Schwald M, Bertschy G, et al. Partial normalization of serum brain-derived neurotrophic factor in remitted patients after a major depressive episode. Neuropsychobiology 2005;51:234-238.

41. Shimizu E, Hashimoto K, Okamura N, Koike K, Komatsu N, Kumakiri C, et al. Alterations of serum levels of brain-derived neurotrophic factor (BDNF) in depressed patients with or without antidepressants. Biol Psychiatry 2003;54:70-75.

42. Lin CF, Juang YY, Wen JK, Liu CY, Hung CI. Correlations between sexual dysfunction, depression, anxiety, and somatic symptoms among patients with major depressive disorder. Chang Gung Med J 2012;35: 323-331.

43. Woo JM, Jeon H, Noh E, Kim HJ, Lee S, Lee K, et al. Importance of re- mission and residual somatic symptoms in health-related quality of life among outpatients with major depressive disorder: a cross-sectional study. Health Qual Life Outcomes 2014;12:188.

44. Garcia-Campayo J, Ayuso-Mateos JL, Caballero L, Romera I, Aragones E, Rodriguez-Artalejo F, et al. Relationship of somatic symptoms with depression severity, quality of life, and health resources utilization in patients with major depressive disorder seeking primary health care in Spain. Prim Care Companion J Clin Psychiatry 2008;10:355-362.

45. Romera I, Fernandez-Perez S, Montejo AL, Caballero F, Caballero L, Arbesu JA, et al. Generalized anxiety disorder, with or without comorbid major depressive disorder, in primary care: prevalence of painful somatic symptoms, functioning and health status. J Affect Disord 2010;127:160-168.

46. Stahl SM, Ahmed S, Haudiquet V. Analysis of the rate of improvement of specific psychic and somatic symptoms of general anxiety disorder during long-term treatment with venlafaxine ER. CNS Spectr 2007; 12:703-711.

47. Deschenes SS, Burns RJ, Schmitz N. Associations between diabetes, major depressive disorder and generalized anxiety disorder comorbidity, and disability: findings from the 2012 Canadian Community Health Survey - Mental Health (CCHS-MH). J Psychosom Res 2015;78:137142.

48. Hunt C, Slade T, Andrews G. Generalized anxiety disorder and major depressive disorder comorbidity in the National Survey of Mental Health and Well-Being. Depress Anxiety 2004;20:23-31.

49. Phillips AC, Batty GD, Gale CR, Lord JM, Arlt W, Carroll D. Major depressive disorder, generalised anxiety disorder, and their comorbidity: associations with cortisol in the Vietnam Experience Study. Psychoneuroendocrinology 2011;36:682-690.

50. Cubeddu A, Bucci F, Giannini A, Russo M, Daino D, Russo N, et al. Brain-derived neurotrophic factor plasma variation during the different phases of the menstrual cycle in women with premenstrual syndrome. Psychoneuroendocrinology 2011;36:523-530.

51. Katerberg H, Lochner C, Cath DC, de Jonge P, Bochdanovits Z, Moolman-Smook JC, et al. The role of the brain-derived neurotrophic factor (BDNF) val66met variant in the phenotypic expression of obsessivecompulsive disorder (OCD). Am J Med Genet B Neuropsychiatr Genet 2009;150B:1050-1062.

52. Simsek S, Uysal C, Kaplan I, Yuksel T, Aktas H. BDNF and cortisol levels in children with or without post-traumatic stress disorder after sustaining sexual abuse. Psychoneuroendocrinology 2015;56:45-51.

53. Shi SS, Shao SH, Yuan BP, Pan F, Li ZL. Acute stress and chronic stress change brain-derived neurotrophic factor (BDNF) and tyrosine kinasecoupled receptor (TrkB) expression in both young and aged rat hippocampus. Yonsei Med J 2010;51:661-671.

54. Tognoli C, Rossi F, Di Cola F, Baj G, Tongiorgi E, Terova G, et al. Acute stress alters transcript expression pattern and reduces processing of proBDNF to mature BDNF in Dicentrarchus labrax. BMC Neurosci 2010; 11:4.

55. van Winkel M, Peeters F, van Winkel R, Kenis G, Collip D, Geschwind $\mathrm{N}$, et al. Impact of variation in the BDNF gene on social stress sensitivity and the buffering impact of positive emotions: replication and extension of a gene-environment interaction. Eur Neuropsychopharmacol 2014;24:930-938.

56. Karege F, Perret G, Bondolfi G, Schwald M, Bertschy G Aubry JM. Decreased serum brain-derived neurotrophic factor levels in major depressed patients. Psychiatry Res 2002;109:143-148.

57. Pan W, Banks WA, Fasold MB, Bluth J, Kastin AJ. Transport of brainderived neurotrophic factor across the blood-brain barrier. Neuropharmacology 1998;37:1553-1561.

58. Karege F, Schwald M, Cisse M. Postnatal developmental profile of brain-derived neurotrophic factor in rat brain and platelets. Neurosci Lett 2002;328:261-264. 